\title{
ГРАФИЧЕСКИЙ МЕТОД ВЫБОРА БУРОВЫХ ДОЛОТ
}

\author{
Попов Анатолий Николаевич', \\ popovan.36@mail.ru
}

\section{Исмаков Рустэм Адипович, ismakovrustem@gmail.com}

\author{
Конесев Геннадий Васильевич, \\ konesev.burenie@mail.ru
}

\author{
Ишбаев Гиният Гарифуллович², \\ bit@burinteh.com \\ 1 Уфимский государственный нефтяной технический университет, \\ Россия, 450061, г. Уфа, ул. Космонавтов, 1. \\ 2000 НПП «Буринтех», \\ Россия, 450029, г. Уфа, ул. Юбилейная, 4/1.
}

Актуальность исследования обусловлена необходимостью выбора перспективных буровых долот на стадии проектирования технологии бурения. Это направление является ресурсосберегающим, минимизирующим объем промысловых испытаний при поиске оптимальных технологических решений.

Цель: разработать уточненную методику выбора буровых долот по статистическим данным о показателях механических свойств горных пород.

Объекты: идентификация буровых долот различных фирм и их выбор в соответствии со статистическими характеристиками механических свойств горных пород. Эти вопросы слабо изучены и вызывают затруднения при проектировании режимов бурения скважин.

Методы: графоаналитическое изучение соответствия типов буровых долот прочностным характеристикам горных пород, определяемым методом одноосного сжатия и методом статического вдавливания штампа с плоским основанием.

Результаты. Для идентификации долот различных изготовителей Международная ассоциация буровых подрядчиков (МАБП) разработала единую классификацию в кодах МАБП. Для отечественной практики возникла дилемма: горные породы охарактеризованы твердостью горных пород по штампу и в категориях, а долота - прочностью горных пород при одноосном сжатии и в кодах МАБП. Предложен переход к показателю прочности горных пород, выраженному в кодах МАБП долота. Это обеспечивает единство характеристик как для долот, так и для горных пород. Соответственно предложены номограммы для выбора долот по статистическим величинам прочности горных пород в кодах МАБП, рассчитанных с надежностью 0,95. Показано, что можно аналогично выбирать долота и при представлении твердости горных пород в категориях. В случае лопастных алмазно-твердосплавных долот их выбор распадается на два этапа: выбор типа вооружения в соответствии с прочностью горной породы в кодах или твердостью в категориях и расчет числа лопастей долота, которое зависит как от прочностных характеристик горной породы, так и от диаметра долота. Для упрощения выбора долот предложено характеризовать буримость выделяемых интервалов бурения не словесно (мягкие, средние и т. Д.) ), а их статистическими характеристиками в кодах МАБП или в категориях буримости с заданной вероятностью.

\section{Ключевые слова:}

Интервал бурения долотом, прочность горных пород в кодах МАБП, твердость горных пород в категориях, номограмма, выбор типа долота в кодах МАБП, численная характеристика буримости.

\section{Введение}

Проектирование режима бурения при наличии данных о механических свойствах горных пород начинается с подбора перспективных типов и классов долот для соответствующих интервалов бурения. Основными затруднениями при решении этой задачи являются разные методы определения показателей механических свойств горных пород в России и за рубежом, а также соответствующее различие в назначении области применения долот разной конструкции. В частности, в России используют метод измерения твердости горных пород при статическом вдавливании штампа (метод Л.А. Шрейнера), а за рубежом - определение прочности методом одноосного сжатия $[1,2]$. В [3] были изучены корреляционные связи между названны- ми показателями свойств и показано, что согласованность этих показателей низкая.

Вопросы совершенствования и выбора шарошечных долот в соответствии с механическими свойствами горных пород рассматриваются в работах $[1,3,4$ и др.]. В основу положены литологические признаки горных пород и их осредненные характеристики буримости. При этом практически не используются статистические характеристики механических свойств горных пород.

Для идентификации долот разных изготовителей Международная ассоциация буровых подрядчиков предложила код (код МАБП, а в латинской интерпретации Code IADC) [5-9]. Код используется во всем мире, в т. ч. и в России. Основу кода в случае шарошечных долот составляют три цифры, 
например 324. Первые две цифры характеризуют прочность горных пород при одноосном сжатии, для которых предназначено долото, а третья цифра - диапазон частот вращения долота, соответствующий конструкции его опоры.

Следует подчеркнуть, что цифры кода характеризуют верхнюю границу прочности породы (верхнюю границу области применения долота). Применение долота в горных породах, твердость или прочность которых превышает этот предел, не допускается из-за большой вероятности поломок элементов вооружения.

\section{Выбор типов шарошечных долот}

Для отечественных долот возникла дилемма: горные породы охарактеризованы одним методом, а долота другим и, кроме того, все измерения имеют разные размерности. В работе [10] предложено перейти к безразмерным величинам, единым как для долот, так и для горных пород, а именно к определению прочности горных пород в кодах долота. В литературе на английском языке прочность на одноосное сжатие обозначается UCS (Unconfined Compression Strength). Поэтому ниже показатели прочности в кодах МАБП будем обозначать буквой $U$. За основу принята классификация шарошечных долот. Величина прочности $U$ в кодах прямо пропорциональна прочности породы $\sigma_{c ж}$ при одноосном сжатии, т. е.

$$
U=0,0556 \sigma_{\text {сж}} \text {. }
$$

Уточненная нами классификация приведена в табл. 1. Для удобства принятия решения о перспективном типе долота предложено использовать номограммы. В каталоге фирмы Security [11] приведены графики областей относительной буримости горных пород шарошечными долотами обоих классов и коды МАБП соответствующих долот. Верхние границы $U_{\text {вв }}$ областей применения долот приняты в соответствии с их кодами. Ширина области $B$ была измерена и рассчитана в соответствии с масштабом графиков и составила для долот 1-го класса $B_{1}=3,36$, а для долот 2-го класса $B_{2}=3,98$ кода прочности горной породы. Для дальнейших расчетов приняты $B_{1}=3,4$, а $B_{2}=4,0$ кода прочности горной породы. Далее была рассчитана нижняя граница $U_{\text {дн }}$ области применения долота. Основным условием соответствия долота горным породам является неравенство (2):

$$
U_{\text {вд }} \geq U_{\text {в }} \text {, }
$$

где $U_{\text {вд }}$ - верхняя граница области применения долота; $U_{\text {в }}$ верхнее значение прочности горной породы с вероятностью 0,95. Ширина области применения долот зависит от их номенклатуры. Чем больше номенклатура, тем уже область применения долот. Поэтому в качестве второй характери-

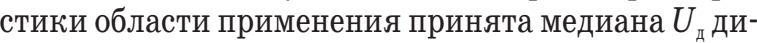
апазона от $U_{\text {дн }}$ до $U_{\text {дв }}$.

На рис. 1 показана номограмма для выбора типов долот 1-го класса (со стальным фрезерованным вооружением). Из табл.1 видно, что по характеристикам в кодах МАБП эти долота разделены на три группы, каждая из которых содержит четыре подгруппы (типа). На номограмме по оси абсцисс отложена прочность горных пород в кодах МАБП. Из начала координат проведена диагональ. На оси

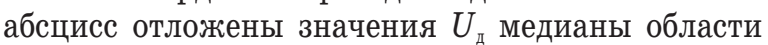
применения каждого типа долот и восстановлены перпендикуляры до пересечения с диагональю. На точках пересечения построены горизонтальные отрезки с абсциссами от $U_{\text {дн }}$ до $U_{\text {дв}}$, представляющие собой области применения соответствующих долот. Ключ к номограмме показан пунктирными линиями.

Таблица 1. Вооружение долот и прочность горных пород в кодах МАБП

Table 1. Armament of bits and toughness of formations in the

\begin{tabular}{|c|c|c|c|}
\hline \multicolumn{2}{|c|}{$\begin{array}{c}\text { Коды шарошечных долот } \\
\text { Codes of roller cone bits }\end{array}$} & \multirow{2}{*}{$\begin{array}{l}\text { Код долот PDC } \\
\text { Code of PDC bits }\end{array}$} & \multirow{2}{*}{$\begin{array}{c}\text { Прочность горной } \\
\text { породы, } U, \text { коды } \\
\text { Strength of formation, } \\
U, \text { codes }\end{array}$} \\
\hline $\begin{array}{c}\text { 1-го класса } \\
1^{\text {st }} \text { class }\end{array}$ & $\begin{array}{l}\text { 2-го класса } \\
2^{\text {nd }} \text { class }\end{array}$ & & \\
\hline- & - & - & 0 \\
\hline 11 & 41 & 1 & 1 \\
\hline 12 & 42 & 1 & 2 \\
\hline 13 & 43 & 1 & 3 \\
\hline 14 & 44 & 2 & 4 \\
\hline 21 & 51 & 2 & 5 \\
\hline 22 & 52 & 2 & 6 \\
\hline 23 & 53 & 3 & 7 \\
\hline 24 & 54 & 3 & 8 \\
\hline 31 & 61 & 3 & 9 \\
\hline 32 & 62 & 4 & 10 \\
\hline 33 & 63 & 4 & 11 \\
\hline 34 & 64 & 4 & 12 \\
\hline- & 71 & - & 13 \\
\hline- & 72 & - & 14 \\
\hline- & 73 & - & 15 \\
\hline- & 74 & - & 16 \\
\hline- & 81 & - & 17 \\
\hline- & 82 & - & 18 \\
\hline- & 83 & - & 19 \\
\hline- & 84 & - & 20 \\
\hline
\end{tabular}
IADC codes

При выборе долота для заданного интервала бурения рассчитываются среднее арифметическое значение $U_{\text {I }}$ и среднее квадратическое отклонение

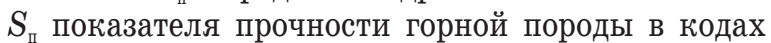
МАБП. Далее по формуле (3) рассчитывается верхнее значение прочности горной породы:

$$
U_{\mathrm{B}}=U_{\text {п }}+t S_{\text {п }} \text {, }
$$

где $t$ - параметр распределения Стьюдента с принятой в бурении надежностью 0,95 [12].

Полученные значения откладываются на номограмме, как показано на рис. 1. Из рис. 1 следует, что области применения долот перекрываются, т. е. одному значению $U_{\text {в }}$ соответствуют несколько типов долот. Поэтому предлагается считать перспективными типы долот ближайшие к горизонтали, проходящей через точку пересечения перпендикуляра из точки $U_{\text {II }}$ и диагонали, но удовлетворяющие условию (2).

В качестве примера принята величина $U_{\text {п1 }}=4,6$ кодов и два значения $U_{\mathrm{B} 1}=5,8$ и $U_{\text {в2 }}=6,5$ ко- 
да. В первом случае горной породе удовлетворяют долота с кодом 22 и 23 , а во втором - только с кодом 23. Далее по каталогам нетрудно подобрать соответствующие долота любой фирмы при известных диаметре и проектируемой частоте вращения. Из рис. 1 видно, что при выборе долот диапазон от $U_{\text {дн }}$ до $U_{\text {д }}$ не используется, а поэтому на номограмме может быть опущен.

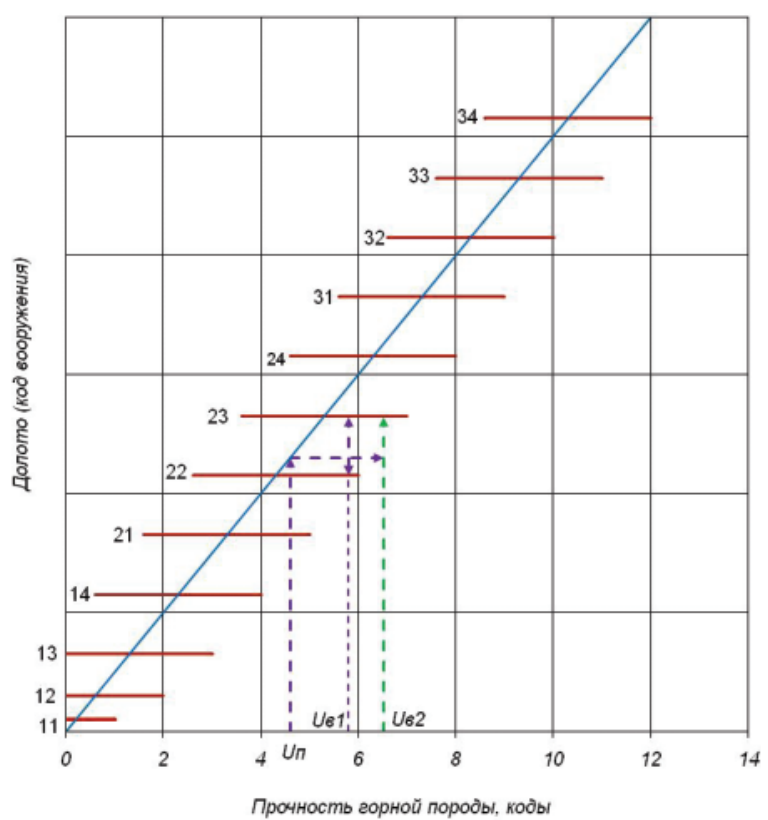

Pис. 1. Номограмма выбора долот 1-го класса

Fig. 1. Nomogram of selection of the $1^{\text {st }}$ class bits

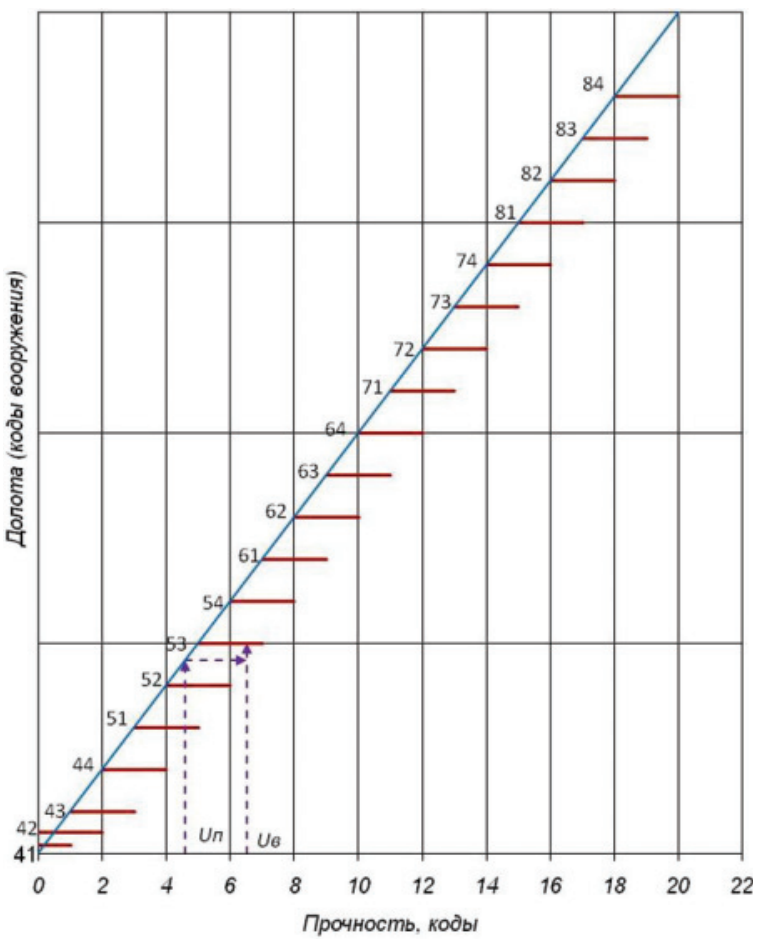

Pис. 2. Номограмма выбора долот 2-го класса

Fig. 2. Nomogram of selection of the $2^{\text {nd }}$ class bit
На рис. 2 показана номограмма для выбора типов долот 2-го класса (с твердосплавным вооружением). Ключ к номограмме аналогичен приведенному на рис. 1 . Например, для горных пород прочностью $U_{\text {п }}=4,6$ и $U_{\text {в }}=6,5$ кода перспективным будет долото с кодом 53.

В нашей стране при выборе долот задается не прочность, а твердость горной породы в категориях. Оценка величины твердости проводится либо по величине твердости горной породы по штампу, либо косвенным методом по шламу. Для перехода от прочности горных пород в кодах к твердости горной породы в категориях воспользуемся прямыми определениями области применения в категориях долот производства ОАО «Волгабурмаш» с известными характеристиками их по коду МАБП [5]. Результаты расчетов проиллюстрированы рис. 3 , из которого следует, что зависимость $H_{\text {дв }}$ от $U_{\text {дв }}$ для шарошечных долот как 1-го, так и 2-го классов описывается уравнением регрессии

$$
H_{\text {дв }}=12\left(1-\exp \left(-0,271 U_{\text {дв }}^{0,59}\right)\right)
$$

при коэффициенте детерминации 0,97. График зависимости $H_{\text {дв } о т ~} U_{\text {дв}}$, рассчитанный по формуле (4), показан сплошной линией (рис. 3). Точками показа-

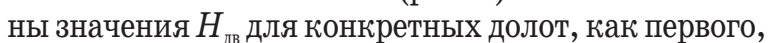
так и второго классов. Для расчета медианы области применения $H_{\text {д }}$ формула (4) принимает вид (5):

$$
H_{\text {д }}=12\left(1-\exp \left(-0,133 U_{\text {д }}^{0,59}\right)\right) \text {. }
$$

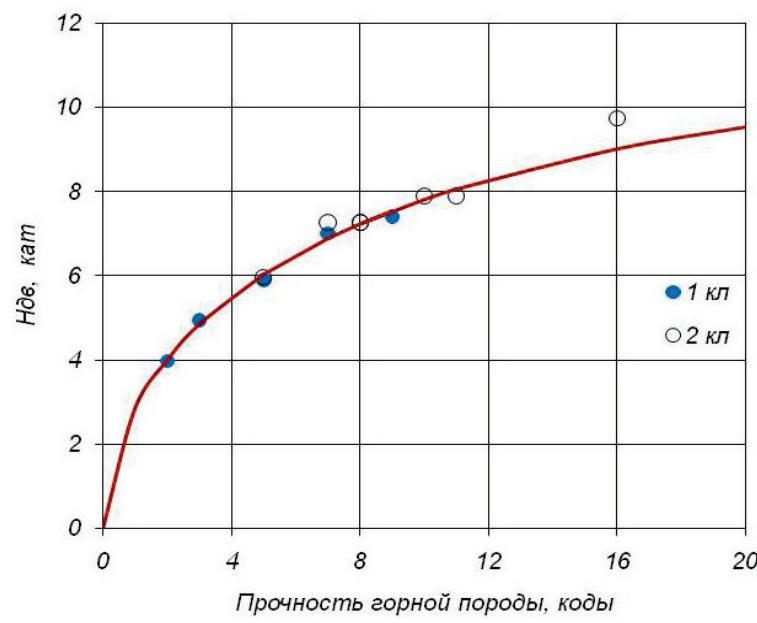

Pис. 3. Зависимость верхних значений твердости горных пород в категориях от прочности горных пород в кодах для шарошечных долот

Fig. 3. Dependence of the upper values of hardness of formations in categories on the toughness of formations in codes for cone bits

По результатам расчетов по формулам (4) и (5) построены номограммы, приведенные на рис. 4,5 . Из сопоставления номограмм на рис. 1,4 видно, что при расчетах по кодам области применения долот по мере перехода к более прочным породам не изменяются, а при расчетах в категориях - быстро сужаются. Из сопоставления номограмм на рис. 2,5 видно, что характер номограмм такой же, как и номограмм на рис. $1,4$. 


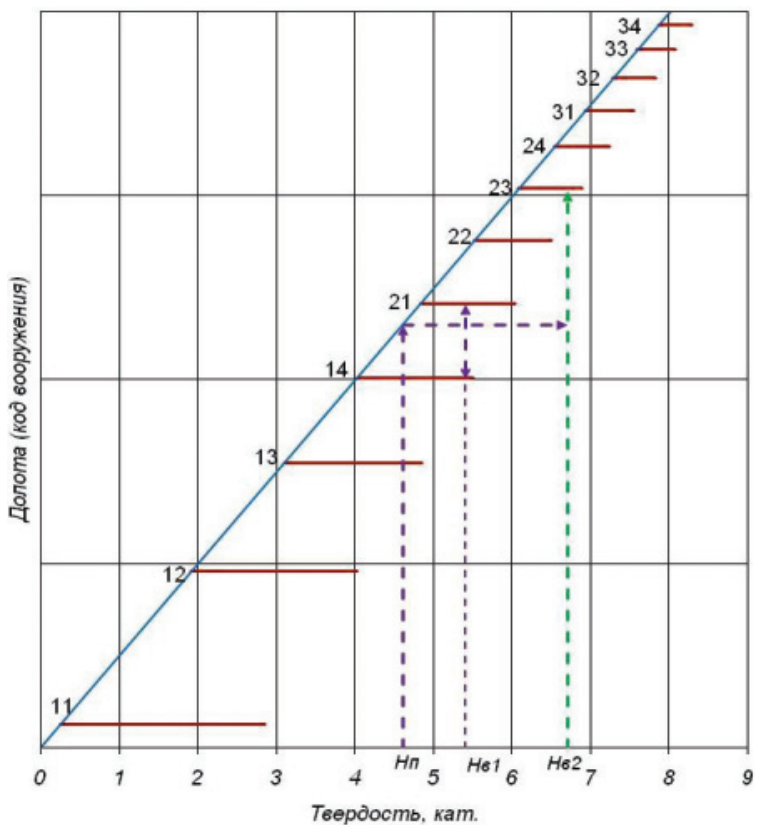

Pис. 4. Номогралма выбора долот 1-го класса по данным о твердости горных пород в категориях

Fig. 4. Nomogram of selection of $1^{\text {st }}$ class bits in accordance with the data on hardness of formations in categories

Различие номограмм обусловлено тем, что прочность горных пород в кодах зависит от прочности на одноосное сжатие линейно (1), а зависимость твердости в категориях от твердости по штампу экспоненциальная [3]. Кроме того, показатели твердости по штампу из-за его малых размеров имеют более высокий коэффициент вариации, и при испытаниях более существенно проявляется масштабный эффект по сравнению с показателями, определяемыми при одноосном сжатии. Это понижает точность выбора долота по данным о твердости горных пород в категориях по сравнению с выбором долота по данным об их прочности в кодах.

На номограммах (рис. 4, 5) показан выбор долота для двух случаев. Для обоих случаев среднее значение твердости горной породы одно и то же $\left(H_{\text {п }}=4,6\right.$ кат), а отличаются случаи только верхними значениями твердости:

1) $H_{\mathrm{B}}=5,4$ кат.;

2) $H_{\mathrm{B}}=6,7$ кат.

Из рис. 4 видно, что в первом случае перспективными являются долота 1-го класса с кодами 14 и 21 , а в во втором случае только долото с кодом 23. А из рис. 5 видно, что в первом случае перспективными являются долота 2-го класса с кодами 44 и 51 , а в во втором случае только долото с кодом 53.

\section{Выбор лопастных алмазно-твердосплавных долот}

Лопастные долота с алмазно-твердосплавным вооружением являются одним из основных породоразрушающих инструментов для бурения скважин на нефть и газ. Эти долота широко известны под аббревиатурой PDC (polycrystalline diamond cutter) $[13,14]$. Исследования конструкций и работы долот PDC направлены в основном на изучение взаимодействия резцов с горной породой $[15,16]$, на способы совершенствования резцов и предупреждения вибраций долот и армирование их рабочих поверхностей [17-19].

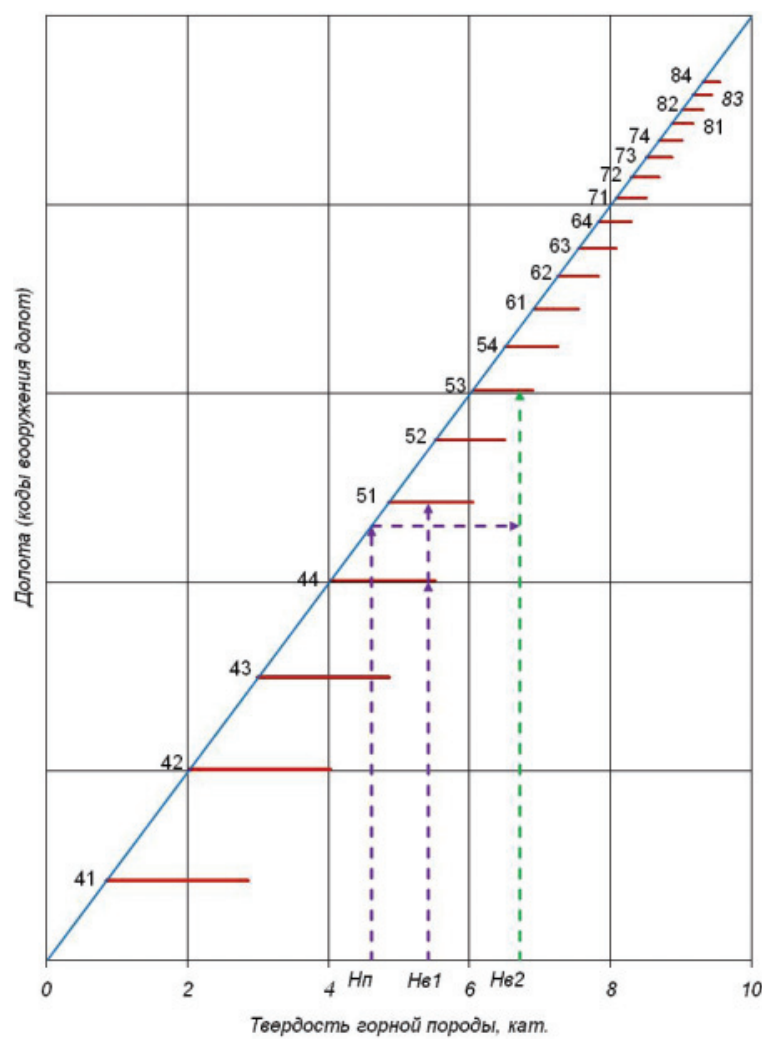

Pис. 5. Номограмла выбора долот 2-го класса по даннылм о твер дости горных пород в категориях

Fig. 5. Nomogram of selection of $2^{\text {nd }}$ class bits in accordance with the data on hardness of formations in categories

Для долот PDC основу кода МАБП составляет одна из двух латинских букв и три цифры, например S232 или M232 [13]. Буквы характеризуют материал головки долота: $\mathrm{S}$ - головка долота стальная, M - головка долота из твердого сплава (матричное долото). Первая цифра характеризует группу прочности горной породы при одноосном сжатии, вторая - группу диаметров резцов, а третья - форму лопастей. В соответствии с группой прочности пород классификация включает четыре типа вооружения долот.

Построение номограммы для выбора долот PDC по кодам было показано ранее [10], поэтому рассмотрим только выбор долот при измерении твердости горных пород в категориях. В табл. 2 приведены сведения о долотах PDC 000 НПП «Буринтех» [20]. Долота PDC оснащаются базовыми резцами и резцами повышенной прочности (опция Т) и износостойкости (опция Y), которые расширяют область применения долот. Крестиком отмечены изготавливаемые конструкции долот. Пропуски в колонках 5-7 табл. 2 означают, что долота этих конструкций не изготавливаются.

Задача распадается на две части: выбор цифры кода типа вооружения и расчет числа лопастей до- 
лота. В [20] приведены области применения долота, которые включают диапазон от нижнего до верхнего значения твердости горной породы в категориях.

Таблица 2. Типы долот PDC и области их применения Table 2. Types of PDC bits and their application fields

\begin{tabular}{|c|c|c|c|c|c|c|}
\hline \multirow[b]{2}{*}{$\begin{array}{c}\text { Тип } \\
\text { долота } \\
\text { Bit } \\
\text { type }\end{array}$} & \multirow{2}{*}{ 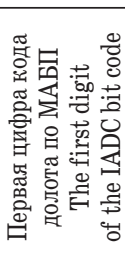 } & \multirow{2}{*}{ 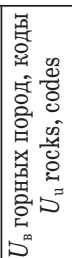 } & \multirow{2}{*}{ 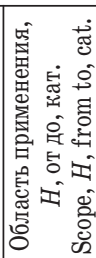 } & \multicolumn{3}{|c|}{$\begin{array}{l}\text { Особенности конструкции } \\
\text { Design of construction }\end{array}$} \\
\hline & & & & $\begin{array}{c}\text { базовая } \\
\text { basic }\end{array}$ & $\begin{array}{c}\text { с опцией } T \\
\text { with } \\
\text { option } T\end{array}$ & $\begin{array}{c}\text { с опцией } Y \\
\text { with } \\
\text { option } Y\end{array}$ \\
\hline $\mathrm{M}$ & 1 & до 3 & $1-4$ & + & & \\
\hline $\mathrm{MC}$ & 2 & до 6 & $2-5$ & + & + & \\
\hline $\mathrm{C}$ & 3 & $\begin{array}{l}\text { до } 9 \\
\end{array}$ & $3-6$ & + & + & \\
\hline CT & $3^{\prime}$ & \begin{tabular}{|l} 
до 9 \\
\end{tabular} & $4-6$ & & + & \\
\hline $\mathrm{T}$ & 4 & до 12 & $4-7$ & & & + \\
\hline
\end{tabular}

Номограмма для выбора типа долота приведена на рис. 6 . В отличие от шарошечных долот на номограмму нанесена не половина, а вся область применения долот. Ключ к номограмме прорисован пунктиром. Например, средняя твердость породы $H_{\text {п }}=4,7$ категории. Для верхнего значения прочности породы примем два случая: 1) $H_{\mathrm{B} 1}=5,7$ категории; 2) $H_{\text {в2 }}=6,5$ категории. Из рис. 6 видно, что в первом случае следует выбрать долото с кодом вооружения 3 и 3', а во втором - только с кодом 4.

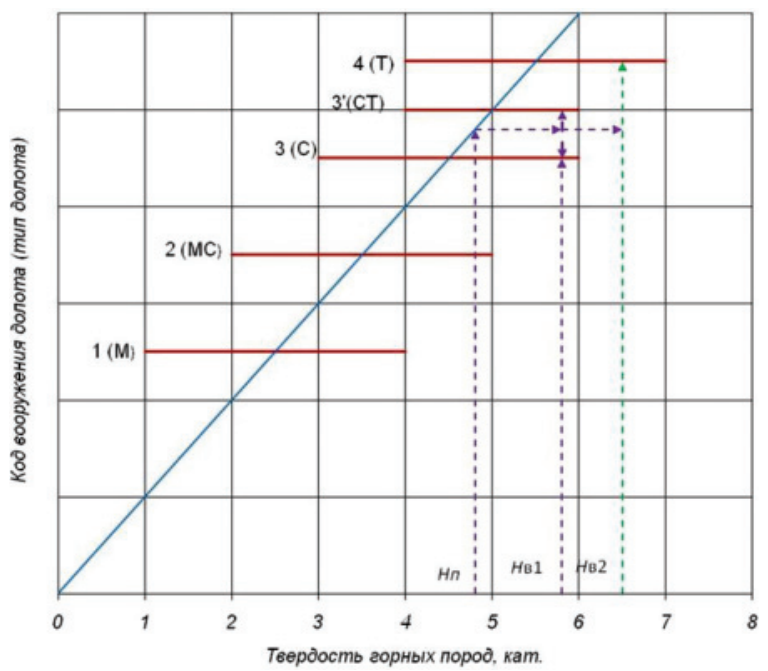

Puc. 6. Номограмма выбора долот PDC

Fig. 6. Nomogram of PDC bits selection

Этот выбор не является окончательным, т. к. число лопастей долота PDC зависит не только от твердости горной породы, но и от диаметра долота. В [13] приведены подробные данные о долотах PDC разных изготовителей. Регрессионный анализ этих данных дал следующие результаты:

- для долот НПП «Буринтех» базовой конструкции

$$
z=0,240 D^{0,234} H_{\mathrm{B}}^{1,052} \text {; }
$$

- для долот НПП «Буринтех» с опциями «T» и «Y»

$$
z=0,00208 D^{0,559} H_{\mathrm{B}}^{2,685} \text {; }
$$

- для долот ОАО «Волгабурмаш»

$$
z=0,00628 D+0,908 H_{\mathrm{B}} ;
$$

- для долот СП «УДОЛ» (Удмуртские долота)

$$
z=0,0102 D^{0,355} H_{\mathrm{B}}^{1,305} \text {, }
$$

где $z$ - число лопастей; $D$ - диаметр долота, мм; $H_{\text {в }}$ верхнее значение твердости горной породы, категории. Коэффициент детерминации составил около 0,97. Расчетное число лопастей желательно округлять в большую сторону. В табл. 3 приведены результаты расчета по формулам (6)-(9).

Таблица 3. Расчетное число лопастей долот диаметром

\begin{tabular}{|c|c|c|c|c|}
\hline \multirow[b]{2}{*}{$\begin{array}{l}\text { Изготовитель } \\
\text { Manufacturer }\end{array}$} & \multicolumn{2}{|r|}{ БУРИНТЕХ } & \multirow[b]{2}{*}{ Волгабурмаш } & \multirow[b]{2}{*}{ удол } \\
\hline & $\begin{array}{c}\text { базовоє } \\
\text { basic }\end{array}$ & \begin{tabular}{|c} 
с опциями «T» и «Y» \\
with options «T» and «Y»
\end{tabular} & & \\
\hline $\begin{array}{l}z, \text { лопастей } \\
z, \text { blades }\end{array}$ & 7 & 6 & 8 & 8 \\
\hline
\end{tabular}
215,9 м.м при $H_{\mathrm{B}}=6,5 \mathrm{kam}$.

Table 3. Estimated number of blades of bits with a diameter of $215,9 \mathrm{~mm}$ and $H_{\mathrm{B}}=6,5 \mathrm{cat}$.

Из табл. 3 видно, что разные изготовители долот рекомендуют хотя и близкие, но несколько отличающиеся числа лопастей. Это обусловлено использованием резцов разных изготовителей, а также целями, которые преследует заказчик. В [10] было показано, что долота с меньшим числом лопастей обеспечивают более высокую механическую скорость бурения, но уступают долотам с большим числом лопастей по проходке на долото.

Использование номограмм предполагает наличие численных характеристик буримости интервалов горных пород, т. е. вместо слов (мягкие, средние и т. д.) должны быть записаны диапазоны численных значений твердости горных пород или в категориях твердости, или в кодах прочности с заданной вероятностью (в бурении принята надежность оценки с вероятностью 0,95). Например, в настоящее время по стратиграфическим подразделениям широко используется определение твердости горных пород в категориях по шламу методом аналогий. По этим данным не составляет труда рассчитать статистические характеристики твердости горной породы, т. е. их нижнее, среднее и верхнее значения. Далее для проектного интервала бурения определить расчетные значения прочностных характеристик горных пород, например $H_{\text {п }}$ и $H_{\text {в }}$, и с использованием номограмм принять решение о перспективных типах долот.

\section{Заключение}

1. Показана целесообразность оценки прочности горной породы по шкале кодов МАБП, составленной на основе кодов шарошечных долот.

2. Предложены номограммы выбора долот в соответствии с прочностью в кодах или с твердостью в категориях горных пород, обеспечивающие высокую наглядность при принятии решения. 
3. Поставлен вопрос о необходимости описывать свойства горных пород по выделяемым интервалам бурения не словесно, а конкретными числа-

\section{СПИСОК ЛИТЕРАТУРЫ}

1. Абатуров В.Г., Овчинников В.П. Физико-механические свойства горных пород и породоразрушающий буровой инструмент. - Тюмень: Изд-во «Экспресс», 2008. - 240 с.

2. Попов А.Н., Трушкин Б.Н., Трушкин О.Б. Разрушение горных пород. - Уфа: Изд-во УГНТУ, 2016. - 138 с.

3. Попов А.Н., Могучев А.И., Попов М.А. Согласование шкал твердости горных пород в категориях с показателями их механических свойств // Строительство нефтяных и газовых скважин на суше и на море. - 2009. - № 12. - С. 18-23.

4. Технология бурения нефтяных и газовых скважин: в 5 т. / В.П. Овчинников, Ф.А. Агзамов, Т.О. Акбулатов, Г.В. Конесев, Р.А. Исмаков, А.Н. Попов, Б.Н. Трушкин, Н.А. Аксенова, Т.В. Грошева, Г.Н. Шешукова / под общ. ред. В.П. Овчинникова. - Тюмень: Изд-во ТИУ, 2017. - Т. 2. - 584 с.

5. Каталог продукции для нефтегазовой промышленности. - Caмара: Волгабурмаш. Уралбурмаш, 2015. - 84 с. URL: htth:/www.vbm.ru/ (дата обращения 28.08.2018).

6. Каталог буровых долот Хьюз Кристенсен. - Хьюстон: Бейкер Хьюз Инкорпорейтед, 2014. - 48 с.

7. Каталог буровых долот Reed Hycalog. - Хьюстон: Grant Prideco Company, 2015. - 34 p. URL: https:/reedmfgco.com/assets/download/4139_Reed-Russion-catalog-2015.pdf (дата обращения 28.08.2018).

8. Varel NTS. - Houston: Varel International, 2010. -48 p.

9. Kingdream roller cone bits for oil well drilling. - Hubey, China, 2018. - 52 p. URL: http:/www.kingdream.com.cn/ (дата обращения 28.08.2018).

10. Попов А.Н., Трушкин О.Б. Согласование типа, диаметра и числа лопастей долот PDC с прочностью горных пород в кодах МАБП // Территория Нефтегаз. - 2017. - № 10. - С. 20-23. ми, представляющими собой диапазон прочности в кодах или твердости в категориях с принятой в бурении надежностью оценки (вероятностью).

11. Security Oilfield Catalog. - Dallas, Texas: Security-Dresser, 2002. $-40 \mathrm{p}$.

12. Ганджумян Р.А. Математическая статистика в разведочном бурении: справочное пособие. - М.: Недра, 1990. - 218 с.

13. Буровой породоразрушающий инструмент. Долота с фиксированными алмазосодержащими резцами: международный транслятор-справочник /И.К. Бикбулатов, Г.И. Вышегородцева, Э.С. Гинзбург, В.Я. Кершенбаум, Ю.Г. Михайлин, Г.Г. Омаров, М.Г. Омаров, А.В. Торгашов, С.А. Цеденов / под ред. В.Я. Кершенбаума. - М.: Изд-во 000 «Национальный институт нефти и газа», 2011. - Т. 2. - 448 с.

14. Polycrystalline Diamond Compact (PDC). - China: Shenzhen Haimingrun Superhard Materials Co., Ltd., 2010. - 16 p.

15. Трушкин 0.Б. Разрушение горной породы единичным резцом PDC // Территория «Нефтегаз». - 2016. - № 5. - С. 16-20.

16. Akbari B., Miska S., Rahmani R. Experimental Investigation of the Effect of the Pore Pressure on the MSE and Drilling Strength of a PDC Bit // SPE Western North America and Rocky Mountain Regional Meeting. - Denver, Colorado, 2014. - V. 8. - P. 16-21.

17. Bellin F. The current state of PDC bit technology // World 0il. September 2010. - № 9. - P. 41-42.

18. Чулкова В.В. Метод выбора долот PDC для перемежающихся по твердости горных пород // Вестник Ассоциации буровых подрядчиков. - 2015. - № 2. - С. 17-19.

19. Хузина Л.Б., Шайхутдинова А.Ф., Хузин Б.А. Анализ и предложение по эффективному применению долот PDC на месторождениях ПАО «Татнефть» // Строительство нефтяных и газовых скважин на суше и на море. - 2017. - № 11. - С. 15-19.

20. Буринтех. Каталог 2017. - Уфа: Изд-во 000 НПП «Буринтех», 2017. -126 c

Поступила 25.12.2018 2.

\section{Информация об авторах}

Попов А.Н., доктор технических наук, профессор кафедры бурения нефтяных и газовых скважин Уфимского государственного нефтяного технического университета.

Исмаков P.A., доктор технических наук, проректор по научной и инновационной работе Уфимского государственного нефтяного технического университета.

Конесев Г.В., доктор технических наук, профессор кафедры бурения нефтяных и газовых скважин Уфимского государственного нефтяного технического университета.

Иибаев Г.Г., доктор технических наук, генеральный директор 000 НПП «Буринтех». 
UDC 622.24(075.8)

\title{
GRAPHIC METHOD OF SELECTING DRILL BITS
}

\author{
Anatoliy N. Popov', \\ popovan.36@mail.ru
}

\section{Rustem A. Ismakov',}

ismakovrustem@gmail.com

\section{Gennadiy V. Konesev',}

konesev.burenie@mail.ru

\author{
Giniyat G. Ishbaev², \\ bit@burinteh.com \\ 1 Ufa State Oil Technical University, \\ 1, Kosmonavtov street, Ufa, 450062, Russia. \\ 2 OOO NPP Burinteh, \\ 4/1, Yubileynaya street, Ufa, 450029, Russia.
}

The relevance of the research is caused by the need to select promising drilling bits at the design stage of drilling technology. This direction is resource saving, minimizing the volume of field trials in the search for optimal technological solutions.

The main aim of the research was to develop an improved method for selecting drilling bits from statistical data on the mechanical properties of formations.

Objects: identification of drilling bits of different firms and their selection in accordance with the statistical characteristics of the mechanical properties of formations. These issues are poorly understood and cause difficulties in the design of well drilling regimes.

Methods: graphoanalytical study of the correspondence of the types of drill bits to the strength characteristics of formations determined by Unconfined Compression Strength and the method of Static indentation of a stamp with a flat base.

Results. The International Association of Drilling Contractors (IADC) has developed a single classification in IADC codes for identification of bits of various manufacturers. For domestic drillers a dilemma arose: formations are characterized by hardness according to the stamp and in categories, and the bits are made in accordance with the strength of the formations in the IADC codes. The authors propose a transition to the index of formation strength, expressed in the codes of the IADC of bits. This ensures the uniformity of characteristics for both bits and rocks. Accordingly the authors proposed nomograms for selection of bits on statistical value of toughness of formations in codes IADC, calculated with reliability of 0,95. It is shown that it is possible to select bit similarly when representing hardness of formations in categories. In the case of blade diamond carbide bits, their choice is divided into two stages: the choice of the type of a bit in accordance with the strength of the formation in codes or with hardness in categories and the calculation of the number of blades of the bit, which depends both on the toughness characteristics of the formation, and on the diameter of the bit. To simplify the choice of bits, it was suggested to characterize the drillability of formations of the allocated intervals not verbally (soft, medium and so on), but by their statistical characteristics in IADC codes or in the categories with a given probability.

\section{Key words:}

Interval of drilling with bit, strength of formation in IADC codes, hardness of formation in categories, nomogram, selection of bit type in IADC codes, numerical characteristics of drillability of formation intervals.

\section{REFERENCES}

1. Abaturov B.G., Ovchinnikov V.P. Fiziko-mekhanicheskie svoystva gornykh porod i porodorazrushayushchiy burovoy instrument [Physical and mechanical properties of formations and drill tools]. Tyumen, Ekspress Publ., 2008. 240 p.

2. Popov A.N., Trushkin B.N., Trushkin 0.B. Razrushenie gornykh porod [Destruction of formations]. Ufa, UGNTU Publ., 2016. 138 p.

3. Popov A.N., Moguchev A.I., Popov M.A. Concordance of rock hardness scales in categories with their mechanical properties indices. Stroitelstvo neftyanykh i gazovykh skvazhin na sushe i na more, 2009, no. 12, pp. 18-23. In Rus.

4. Ovchinnikov V.P., Agzamov F.A., Akbulatov T.O., Konesev G.V., Ismakov R.A., Popov A.N., Trushkin B.N., Aksenova N.A., Grosheva T.V., Sheshunova G.N. Tekhnologiya bureniya neftyanykh i gazouykh skvazhin [Technology of drilling oil and gas well]. Ed. by V.P. Ovchinnikov. Tyumen, TIU Publ., 2017. Vol. 2, 584 p.

5. Catalog produktsii dlya neftegazovoiy promyshlennosti [Catalogue of products for oil and gas industry]. Samara, Volgaburmash. Uralburmash Publ., 2015. 84 p. Available at: htth:/www. vbm.ru/ (assessed 28 August 2018).
6. Catalog burovykh dolot Hughes Christensen [Catalogue of Hughes Christensen drilling bits]. Houston, Baker Hughes Incorporated, $2014.48 \mathrm{p}$.

7. Catalog burovykh dolot ReedHycalog [Catalogue of ReedHycalog drilling bits]. Houston, Grant Prideco Company, 2015. $34 \mathrm{p}$. Available at: https: //reedgco.com/assets/download/4139_ReedRussian-catalog-2015.pdf (assessed 28 August 2018).

8. Varel NTS. Catalog produktsii [Varel NTS. Product catalogue]. Houston, Varel International, 2010. 48 p.

9. Kingdream roller cone bits for oil well drilling. Hubey, China, 2015. 52 p. Available at: htth:/www.kingdream.com.cn/ (accessed 28 August 2018).

10. Popov A.N., Trushkin O.B. Concordance of type, diameter and number of PDC bit blades with rock strength in MABP codes. Territoriya Neftegaz, 2017, no. 10, pp. 20-23. In Rus.

11. Security Oilfield Catalog. Dallas, Texas, Security-Dresser, 2002. $40 \mathrm{p}$.

12. Gandzhumyan R.A. Matematicheskaya statistika v razvedochnom burenii: spravochnoe posobie [Mathematical statistics in exploration drilling: reference guide]. Moscow, Nedra Publ., 1990. 218 p. 
13. Bikbulatov I.K., Vyshegorodtseva G.I., Ginsburg E.S., Kershenbaum V.Ya., Mikhaylin Yu.G., Omarov G.G., Omarov M.G., Torgashov A.V., Sedenov S.A. Burovoy porodorazrushayushchiy in strument. Dolota s fiksirovannymi almazosoderzhashchimi reztsami [Drill rock cutting tool. Bits with fixed diamond-containing cutters]. Ed. by V.Ya. Kershenbaum. Moscow, Natsionalny institut nefi i gaza Publ., 2011. Vol. 2, 448 p.

14. Polycrystalline Diamond Compact (PDC). China, Shenzhen Haimingrun Superhard Materials Co., Ltd., 2010.16 p.

15. Trushkin 0.B. rock failure by PDC teeth. Territoriya «Neftegaz», 2016, no. 5, pp. 16-20. In Rus.

16. Akbari B., Miska S., Rahmani R. Experimental Investigation of the Effect of the Pore Pressure on the MSE and Drilling Strength of a PDC Bit. SPE Western North America and Rocky Mountain Regional Meeting. Denver, Colorado, 2014. Vol. 8, pp. 16-21.

\section{Information about the authors}

Anatoliy N. Popov, Dr. Sc., professor, Ufa State Oil Technical University.

Rustem A. Ismakov, Dr. Sc., professor, Ufa State Oil Technical University.

Gennadiy V. Konesev, Dr. Sc., professor, Ufa State Oil Technical University.

Ginijat G. Ishbaev, Dr. Sc., professor, General Director, «Burintekh», Ltd.
17. Bellin F. The current state of PDC bit technology. World Oil, September 2010, no. 9, pp. 41-42.

18. Chulkova V.V. Method for selecting the PDC bits for hardness alternating rocks. Vestnik assotsiatsii burovykh podryadchikov, 2015, no. 2, pp. 17-19. In Rus.

19. Khuzina L.B., Shaykhutdinova A.F., Khuzin B.A. Analysis and proposal on effective application of PDC bits on Tatneft deposits. Stroitelstvo neftyanykh i gazovykh skvazhin na sushe i na more, 2017, no. 11, pp. 15-19. In Rus.

20. Burintekh. Katalog 2017 [Burintekh. Catalogue 2017]. Ufa, 000 NPP «Burintekh» Publ., 2017. 126 p.

Received: 25 December 2018. 